\title{
Selective reactions to different killer whale call categories in two delphinid species
}

\author{
Matthew T. Bowers ${ }^{1,2, *}$, Ari S. Friedlaender ${ }^{2,3}$, Vincent M. Janik ${ }^{4}$, Douglas P. Nowacek ${ }^{1,5}$, Nicola J. Quick ${ }^{1}$, \\ Brandon L. Southall ${ }^{2}$ and Andrew J. Read ${ }^{1}$
}

\begin{abstract}
The risk of predation is often invoked as an important factor influencing the evolution of social organization in cetaceans, but little direct information is available about how these aquatic mammals respond to predators or other perceived threats. We used controlled playback experiments to examine the behavioral responses of short-finned pilot whales (Globicephala macrorhynchus) off Cape Hatteras, NC, USA, and Risso's dolphins (Grampus griseus) off the coast of Southern California, USA, to the calls of a potential predator, mammal-eating killer whales. We transmitted calls of mammal-eating killer whales, conspecifics and baleen whales to 10 pilot whales and four Risso's dolphins equipped with multi-sensor archival acoustic recording tags (DTAGs). Only playbacks of killer whale calls resulted in significant changes in tagged animal heading. The strong responses observed in both species occurred only following exposure to a subset of killer whale calls, all of which contained multiple non-linear properties. This finding suggests that these structural features of killer whale calls convey information about predatory risk to pilot whales and Risso's dolphins. The observed responses differed between the two species; pilot whales approached the sound source while Risso's dolphins fled following playbacks. These divergent responses likely reflect differences in anti-predator response mediated by the social structure of the two species.
\end{abstract}

KEY WORDS: Antipredator behavior, Acoustic discrimination, Non-linear acoustics, Pilot whales, Risso's dolphins

\section{INTRODUCTION}

Most animals must balance the demands of avoiding predation with other essential activities such as resource defense, foraging and mating. The threat-sensitive hypothesis predicts that in balancing predator avoidance with other activities, natural selection will favor survival of potential prey which recognize and respond appropriately to a given level of a potential threat (Helfman, 1989). Several empirical studies have shown that prey are capable of perceiving the level of predation risk and demonstrating a proportional response. This may be related to the frequency of predation attempts, a likely

\footnotetext{
${ }^{1}$ Division of Marine Science and Conservation, Nicholas School of the Environment, Duke University, Beaufort, NC 28516, USA. ${ }^{2}$ Southall Environmental Associates, Inc., 9099 Soquel Drive, Suite 8, Aptos, CA 95003, USA. ${ }^{3}$ nnstitute for Marine Sciences, University of California Santa Cruz, 115 McAllister Way, Santa Cruz, CA 95060, USA. ${ }^{4}$ Sea Mammal Research Unit, Scottish Oceans Institute, University of St Andrews, East Sands, St Andrews, Fife KY16 8LB, UK. ${ }^{5}$ Electrical and Computer Engineering, Pratt School of Engineering, Duke University, Durham, NC 27708, USA.

*Author for correspondence (mtb16@duke.edu)

(D) M.T.B., 0000-0001-8974-7829
}

explanation for both waterfowl and deer species fleeing from humans at greater distances during months when recreational hunting is permitted than when it is not (Madsen and Fox, 1995; De Boer et al., 2004; Thiel et al., 2007). Alternatively, experience with predators and direct observation of their behavior may sensitize prey to behavioral cues that reveal the predator's intent or motivation, and, over time, lead to modifications in prey behavior that reduce risk of predation (Stankowich and Blumstein, 2005). There is evidence that animals may perceive subtle postural, locomotive, olfactory and auditory cues about the lethality of the predator (Caro, 2005). For example, both birds and primates appear to assess the predatory threats of snakes based on their posture and head orientation (Etting and Isbell, 2014; Cantwell et al., 2016). Damselfish responded more strongly to larger predator models and to models oriented in a strike mode than to smaller and non-attacking models (Helfman, 1989), and models of sparrow hawks (Accipiter nisus) presented as gliding elicited stronger and more prolonged responses in red knots (Caldrus canutis) than less-threatening perched models (Mathot et al., 2009). California ground squirrels (Spermophilus beecheyi beecheyi) are able to assess the level of danger presented by northern Pacific rattle snakes (Crotalus viridis oreganus) by discriminating between acoustic cues that contain information about both body size and temperature (Swaisgood et al., 1999).

Most of these recognition mechanisms are likely present from birth, with a large genetic influence on the reaction. However, learning may also be involved in predator avoidance. One of the most striking examples of predator recognition comes from harbor seals (Phoca vitulina), in British Columbia, Canada, which recognize the call-type repertoire of fish-eating killer whales in their environment and only show avoidance when exposed to killer whale calls outside this repertoire (Deecke et al., 2002). Killer whales present an interesting predator type in the context of predator recognition. Several killer whale ecotypes exist, and each ecotype specializes on different prey types (Ford and Ellis, 2014). In the coastal Pacific Northwest, sympatric ecotypes occur, most notably mammal-eating ('transient') and fish-eating ('resident') killer whales (Ford et al., 1998; Saulitis et al., 2000). These two ecotypes represent either predators or potential food competitors to other marine mammals. Ecotypes show a clear separation in behavior and reproduction and are genetically distinct (for review, see de Bruyn et al., 2013). Therefore, one could hypothesize that harbor seals simply recognize the call features of fish-eating killer whales from birth, perhaps showing a genetic predisposition in their predator-recognition strategies. However, when non-sympatric fisheating killer whale sounds were played, harbor seals also showed avoidance (Deecke et al., 2002). Furthermore, killer whale calls are influenced by vocal learning and therefore change over time (Deecke et al., 2000). Thus, the seals would have had to learn the calls that do not signal danger to show this discrimination in their predator-avoidance behavior. 
If animals discriminate call types in the recognition of predator calls, prey might also be able to assess when the same individual predators pose a threat and when they do not. This would provide a selective advantage when trying to optimize foraging efficiency. Mammal-eating killer whales are mostly silent while hunting because of the sensitive hearing of their prey and appear to engage in high levels of vocal behavior only after successful prey capture or during periods of social activity (Deecke et al., 2005, 2011). Mammal-eating killer whales, like all forms of this species, have an extremely varied vocal repertoire, including tonal whistles, echolocation clicks and pulsed calls (Ford, 1989; Deecke et al., 2005). The pulsed calls of killer whales are highly stereotyped and can be automatically categorized according to their structural properties (Deecke et al., 2005; Deecke and Janik, 2006). While harbor seals seemed to respond to all mammal-eating killer whale sounds, the killer whale call variety presents an opportunity for prey to discriminate between different predator calls used by the same individuals and adjust their own behavioral reactions depending on the information given in predator calls.

In our study, we hypothesized that killer whale prey with complex cognitive skills, namely other delphinids (Güntürkün, 2014), would display differential behavioral responses to different killer whale calls. For our study subjects, we chose short-finned pilot whales and Risso's dolphins, species that both have been found in the stomachs of killer whales (Jefferson et al., 1991) and are widely distributed offshore, encountering killer whales on a regular basis (Jefferson et al., 1991). In addition, Risso's dolphins are capable of vocal learning (Favaro et al., 2016), while the acoustic features of shortfinned pilot whale calls are similar to those of killer whale calls (Sayigh et al., 2013), making these species of special interest for our study. Finally, the two study species possess different patterns of social organization, so we expected them to exhibit divergent responses to the calls of potential predators.

\section{MATERIALS AND METHODS}

Playback experiments were conducted with 10 pilot whales (Globicephala macrorhynchus Gray 1846) off Cape Hatteras, $50 \mathrm{~km}$ east of Oregon Inlet, NC, USA, between May and September in 2012 and 2014, and with four Risso's dolphins [Grampus griseus (G. Cuvier 1812)] off the coast of Southern California, USA, near Catalina Island in August of 2013 and 2014. All playbacks were performed in Beaufort sea states of $0-3$ so that it was possible to observe behavioral responses at the surface. In addition, each focal animal was tagged with a recording tag (DTAG) that recorded acoustic as well as movement data.

Field research on short-finned pilot whales off Cape Hatteras was conducted under: NOAA Permit 1421-03, issued to Peter Tyack; NOAA Permit 779-1633, issued to Keith Mullin; and NOAA General Authorization 16185, issued to A.J.R. and approved by the Institutional Animal Use and Care Committee of Duke University.

\section{Experimental protocol}

Two small vessels were employed in each field trial: a source vessel (SV) and a small rigid-hulled inflatable boat as the observation vessel (OV). The OV approached each group and selected a wellmarked adult for tagging. A version 2 or 3 DTAG (Johnson and Tyack, 2003) with an anticipated deployment time of $4 \mathrm{~h}$ was attached to the dorsal fin or dorsal surface of the target animal with four small silicone suction cups using a hand-held carbon fiber pole. DTAGs have a programmable time release that vents the suction cups to release the tag from the animal for recovery and download of the data. Females with dependent calves were avoided and, as a condition of the project's permits, playbacks were not performed to groups of either species that contained neonates. Furthermore, our permit limited us to a maximum of three approaches for tagging to minimize stress for the animal. Once an animal was tagged, the OV did not approach closer than $75 \mathrm{~m}$ for at least $60 \mathrm{~min}$ before playbacks were conducted. The SV never approached the animals closer than $200 \mathrm{~m}$. Numerous studies have found that cetaceans return to pre-tagging/approach behavior within 1-2 dive cycles or a short period of time and, therefore, their behavior after this time can be considered 'normal' (e.g. Williamson et al., 2016).

In each playback trial, the focal animal was presented with three sets of acoustic stimuli or exemplars: (1) calls of mammal-eating killer whales recorded from DTAGs off the Pacific coast of the USA and Canada, and North East Atlantic, Shetland, UK (the sound of potential predators); (2) pilot whale social sounds recorded using DTAGs in Tenerife, Spain, or Risso's dolphins recorded with DTAGs off the coast of Southern California (the sound of conspecifics); and (3) humpback whale social sounds recorded with DTAGs from the Stellwagen Bank National Marine Sanctuary, off Cape Cod, MA, USA, as a control. Because of the limited availability of recordings, the conspecific calls used in Southern California came from the same population of Risso's dolphins. All exemplars were generated from high signal to noise ratio recordings and normalized to have an equivalent maximum root mean square (RMS) voltage using a $200 \mathrm{~ms}$ RMS window.

Fifty minutes after the DTAG was attached, the SV moved from a position several kilometers away to a position approximately 200 $500 \mathrm{~m}$ from (but not directly ahead of) the tagged whale. Sound playbacks commenced $60 \mathrm{~min}$ after the DTAG was attached. Observers on the OV tracked the focal (tagged) animal and recorded behavioral data on the individual and its associated group for the duration of the tag deployment. Observations were conducted at about $50 \mathrm{~m}$ from the surfacing animals during playback trials. Observers engaged in all-event sampling (Altmann, 1974), looking for behaviors associated with an anti-predator response, including changes in group size, group spread, surfacing synchrony, heading synchrony, distance from the focal animal to its nearest neighbor, distance to the closest group of conspecifics and activity level including rapid movement, splashing and/or breaching. Altmann (1974) noted all-event sampling is appropriate for recording behaviors such as a response to a threatening vocalization. The all-event surface observations were used to create a qualitative description of the response of focal animals and their groups to the playbacks to add detail to the quantitative measures used as response variables described below. Observers on the $\mathrm{OV}$ were blind to the playback sequence and identity of the exemplar, to avoid any potential for observer effects (Deecke, 2006).

The stimulus groups (mammal-eating killer whale calls, conspecific controls and heterospecific controls) were presented in a randomized sequence and spaced 30 min apart. Each exemplar set consisted of seven repeats of a single exemplar from one of the three stimulus groups spaced $4 \mathrm{~s}$ apart. Each exemplar was relatively short in duration $(\sim 0.5-1 \mathrm{~s})$ and the entire presentation of an exemplar set lasted no more than $34 \mathrm{~s}$. Stimuli were presented to focal animals and their groups through a custom sound source built by Applied Physical Sciences Corporation (APS, Groton, CT, USA) capable of transmitting a flat frequency response from 0.5 to $10 \mathrm{kHz}$. The requested source levels for all calls were RMS normalized to $168 \mathrm{~dB}$ re. $1 \mu \mathrm{Pa}$. We chose this source level to match naturally occurring source levels for killer whales and used balanced levels for playbacks of other species to ensure that all stimuli were presented at equivalent levels, to avoid cues based solely on level (Deecke, 
2006). Each exemplar (calls from each species) was unique and used only once in trials with each species, to avoid pseudo-replication. That is, we used the same exemplars for both Risso's dolphins and pilot whales, but an exemplar was not used for multiple subjects within the same experimental species. Finally, each playback trial occurred at a predetermined time and we did not control for behavioral context.

\section{Processing received stimuli}

Playback signals were identified on the DTAG records and customwritten scripts for MATLAB 8.0 (MathWorks, Natick, MA, USA) were used to calculate broadband maximum received levels (RLs) from measurements made in $200 \mathrm{~ms}$ windows for the duration of the playback (Table 1). The MATLAB scripts used transient elimination algorithms on all signals to exclude energy from short, intense sounds such as echolocation clicks and allow for accurate calculation of the RLs (as described in Tyack et al., 2011).

\section{Analysis of movement}

We analyzed individual responses to playback trials in terms of physical movement towards or away from the sound source using the estimated heading of focal pilot whales and Risso's dolphins as the main response variable. We estimated the focal animal's location and heading at each available surfacing using range and bearing from the OV. Because of the irregularly spaced data, we used a movement model to predict the location of the focal animal at $30 \mathrm{~s}$ increments for the duration of the experiment. We fitted a continuous time-correlated random walk model (CTCRW) to the location data using the R package crawl (https://CRAN.R-project. org/package $=$ crawl). To calculate the range and s.d. of each location estimate, we simulated 100 tracks from the posterior distribution of the CTCRW model and calculated the range of distances and bearings between the focal animal and the sound source immediately prior to the playback and for the $30 \mathrm{~min}$ following each playback. We evaluated whether the animal changed its heading by running a Watson-Williams multi-sample test for equal means (Berens, 2009) on the heading data collected on the DTAG for the 2 min before and after each playback. The WatsonWilliams test is used for circular data and is the equivalent of a two-sample $t$-test for equal angular means. For the animals that made a change in heading, we evaluated the change relative to the source using the estimated path, range and bearing to the source. After observing a strong pattern of heading changes associated with playbacks of certain calls from mammal-eating killer whale calls, we grouped these calls and compared sound types with responses to those without.

In addition, we calculated mean overall dynamic body acceleration (ODBA) (Qasem et al., 2012) of the focal animal in $30 \mathrm{~s}$ time steps and evaluated it against four treatments - baseline, before, during and after - for each call type with a Gaussian general estimating equation (GEE) using the geepack package (Højsgaard et al., 2006) in R statistical software (http://www.R-project.org/). We chose $30 \mathrm{~s}$ time bins to match the duration of the exemplar sets. GEEs have been used in a number of other playback experiments with cetaceans to test stimulus effects (Curé et al., 2012, 2015; Visser et al., 2016; Quick et al., 2017; Sivle et al., 2016; Isojunno et al., 2016). To deal with the repeated measures in the experimental design, we specified a blocking unit (focal ID), which allowed for within-subject correlation of residuals but assumes independence between blocking units. Data from two concurrently tagged animals (Gm14_178a and b) were placed in the same blocking unit and were not assumed to be independent. All other tags were deployed in independent observation periods. We ran models with an independent and autoregressive correlation structure and used the ANOVA method to compare each model by Wald tests. In each case, the independent correlation structure was determined to be a better model. Each treatment was compared with the baseline using $95 \%$ confidence intervals derived from a parametric bootstrap of 10,000 iterations on the fit parameters of the GEE. For the bootstrap, we assumed a multivariate normal distribution with means equal to the estimated parameters from the model and the variancecovariance matrix from the fitted model.

We also assessed each playback qualitatively by plotting data from the DTAG, including the acoustics spectrogram, flow noise (noise power at $500 \mathrm{~Hz}$ band-pass filtered with a 2-pole Butterworth filter), ODBA, depth and heading for the $30 \mathrm{~s}$ before, during and after each playback (Fig. 1). Flow noise and ODBA were calculated following procedures outlined in prior studies (Simon et al., 2009; Qasem et al., 2012).

\section{Analysis of social calls}

We counted calls on the DTAG record in a 5 min baseline period (10 min before presentation of any stimulus) and for $5 \mathrm{~min}$ before and after each stimulus. We did not analyze call counts during the playbacks because of the high levels of background noise (flow noise and splashing) which occurred on a number of the playbacks. We excluded feeding buzzes and clicks as defined in Soto et al. (2008) from our social call counts. We included whistles, burst pulses and rasps (Soto et al., 2012). These call counts were binned into $30 \mathrm{~s}$ time steps and analyzed with a Poisson GEE using the geepack package (Højsgaard et al., 2006) in R statistical software (http://www.Rproject.org/), following the same procedures as described above.

\section{Analysis of playback stimuli}

We analyzed each exemplar for non-linear components including biphonation, deterministic chaos, subharmonics and frequency jumps (Fitch et al., 2002). As toothed whales have two sound generators, bi-phonation might not be a non-linear phenomenon in this species. However, the resulting two-component call is a typical non-linear call type for the receiver, so we included this phenomenon here.

In addition, spectrograms of each of the killer whale exemplars were visually categorized based on their ARTwarp classification results from earlier studies (Deecke, 2003; Deecke and Janik, 2006) to determine whether certain call types were eliciting a response. Non-linear components were identified through visual inspection and by calculation of Lyapunov exponents of spectrograms following previously applied methods (Tyson et al., 2007). The calls were analyzed in MATLAB using fast Fourier transformations (FFTs), with 2048 point FFTs, Hanning windows and a 75\% overlap of successive windows. Identification of deterministic chaos was achieved using the open TSTOOL package (version 1.2; http:// www.physik3.gwdg.de/tstool/index.html). We used the method of surrogate data to test the null hypothesis that the signals were produced by a stationary, linear, random Gaussian process (Theiler et al., 1992; Tyson et al., 2007). Surrogate data for each call were produced using the surrogatel function and follow the approach used by Theiler et al. (1992), which creates the surrogate signal by phase-randomizing the data. Lyapunov exponents were calculated for both the original and surrogate data using the largelyap function. The largelyap function requires an embedding delay, which was calculated using the amutual function and an embedded dimension which was determined using the cao function. We then performed paired $t$-tests on the Lyapunov exponents from the surrogate and 
Table 1. Stimulus order, exemplars, maximum root mean square (RMS; $d B$ re. $1 \mu \mathrm{Pa}$ ) broadband received levels (Max. RL) and group context for all playbacks

\begin{tabular}{|c|c|c|c|c|c|c|c|c|c|c|c|}
\hline \multirow[b]{2}{*}{ ID } & \multirow[b]{2}{*}{$\begin{array}{l}\text { Stimulus } \\
\text { order }\end{array}$} & \multicolumn{3}{|c|}{ Humpback exemplar } & \multicolumn{3}{|c|}{ Conspecific exemplar } & \multicolumn{3}{|c|}{ Killer whale exemplar } & \multirow[b]{2}{*}{ Group context } \\
\hline & & Exemplar & $\begin{array}{c}\text { Est. } \\
\text { distance } \\
(\mathrm{m})\end{array}$ & $\begin{array}{l}\text { Max. } \\
\text { RL } \\
\text { (dB) }\end{array}$ & Exemplar & $\begin{array}{c}\text { Est. } \\
\text { distance } \\
(\mathrm{m})\end{array}$ & $\begin{array}{c}\text { Max } \\
\text { RL } \\
(\mathrm{dB})\end{array}$ & Exemplar & $\begin{array}{c}\text { Est. } \\
\text { distance } \\
(\mathrm{m})\end{array}$ & $\begin{array}{l}\text { Max. } \\
\text { RL } \\
(\mathrm{dB})\end{array}$ & \\
\hline
\end{tabular}

\begin{tabular}{|c|c|c|c|c|c|c|c|c|c|c|c|}
\hline Gm12_125b & $\mathrm{K}-\mathrm{C}-\mathrm{H}$ & $\mathrm{Mn}-10$ & $300-460$ & $102^{*}$ & $\mathrm{Gm}-1$ & $250-440$ & 133 & Oo-5 & $200-320$ & 137 & $\begin{array}{l}10 \text { animals, increased } \\
\text { to } 14 \text {. }\end{array}$ \\
\hline Gm12_133a & $\mathrm{H}-\mathrm{C}-\mathrm{K}$ & Mn-1 & $350-590$ & 118 & $\mathrm{Gm}-9$ & $240-410$ & $119^{*}$ & Oo-24 & $410-480$ & $110^{*}$ & $\begin{array}{l}\text { Solitary animal, joined } \\
\text { up with } 4 \text { others before } \\
\text { the playback, } 2 \text { of which } \\
\text { were a mother-calf pair. }\end{array}$ \\
\hline Gm12_162a & $\mathrm{K}-\mathrm{H}-\mathrm{C}$ & $\mathrm{Mn}-21$ & $440-520$ & 120 & Gm-18 & $460-570$ & $117^{*}$ & Oo-19 & $470-570$ & 122 & $\begin{array}{l}10 \text { animals, spread out, } \\
\text { mostly mother/calf pairs. }\end{array}$ \\
\hline Gm12_172a & $\mathrm{C}-\mathrm{H}-\mathrm{K}$ & $\mathrm{Mn}-17$ & $520-650$ & $X^{*}$ & Gm-15 & $480-600$ & 124 & Oo-9 & $220-370$ & 135 & $\begin{array}{l}14 \text { whales, spread out, } \\
\text { decreased to } 9 \text { before } \\
\text { the playbacks. }\end{array}$ \\
\hline
\end{tabular}

\begin{tabular}{|c|c|c|c|c|c|c|c|c|c|c|c|}
\hline Gm12_246a & C-H-K & $\mathrm{Mn}-7$ & $240-320$ & 125 & $\mathrm{Gm}-11$ & $400-470$ & 122 & Oo-22 & $340-430$ & $118^{*}$ & $\begin{array}{l}16 \text { whales, fairly tight, } \\
\text { consisting of multiple } \\
\text { mother-calf pairs. }\end{array}$ \\
\hline
\end{tabular}

\begin{tabular}{|c|c|c|c|c|c|c|c|c|c|c|c|}
\hline Gm14_145a & $\mathrm{H}-\mathrm{C}-\mathrm{K}$ & $\mathrm{Mn}-4$ & $270-340$ & 112 & Gm-16 & $270-420$ & 120 & Oo-10 (-) & $320-360$ & 120 & $\begin{array}{l}15 \text { whales, several } \\
\text { sub-adults and at least } \\
2 \text { mother-calf pairs. }\end{array}$ \\
\hline
\end{tabular}

Gm14_167a K-C-H Mn-15 280-400 $122 \quad$ Gm-10 $230-330 \quad 111^{*} \quad$ Oo-7 (-) $220-300 \quad 125$

22 whales, consisting of two subgroups of 14 and 8 that split and joined throughout the playback.

\begin{tabular}{|c|c|c|c|c|c|c|c|c|c|c|c|}
\hline Gm14_178a & $\mathrm{H}-\mathrm{C}-\mathrm{K}$ & $M n-14$ & $180-270$ & 127 & Gm-13 & $220-460$ & $121^{*}$ & Oo-8 (-) & $200-330$ & 127 & $\begin{array}{l}10 \text { whales, joined a } \\
\text { large aggregation of }\end{array}$ \\
\hline Gm14_178b & $\mathrm{H}-\mathrm{C}-\mathrm{K}$ & $\mathrm{Mn}-14$ & - & 126 & $\mathrm{Gm}-13$ & - & $x$ & Oo-8 (-) & - & 121 & $\begin{array}{l}\text { several hundred during } \\
\text { the experiment. }\end{array}$ \\
\hline Gg13_227b & $\mathrm{C}-\mathrm{K}$ & $x$ & - & $\mathrm{J}$ & $\mathrm{Gg}-1$ & $380-420$ & 118 & Oo-2 & $380-470$ & $123^{*}$ & $\begin{array}{l}12-16 \text { whales in } \\
\text { scattered formation with } \\
\text { high activity. }\end{array}$ \\
\hline Gg13_228b & $\mathrm{K}-\mathrm{C}-\mathrm{H}$ & $M n-23$ & $270-350$ & $121^{*}$ & $\mathrm{Gg}-3$ & $330-440$ & 127 & Oo-10 (+) & $290-410$ & 124 & $\begin{array}{l}14-16 \text { whales in a } \\
\text { relatively tight formation, } \\
\text { slow travel. }\end{array}$ \\
\hline Gg13_231c & $\mathrm{H}-\mathrm{K}-\mathrm{C}$ & $M n-18$ & $280-370$ & $115^{*}$ & $\mathrm{Gg}-8$ & $390-430$ & 121 & Oo-4 & $350-500$ & 129 & $\begin{array}{l}10 \text { whales in tight } \\
\text { formation with another } \\
\text { subgroup of } 10 \text { nearby, } \\
\text { slow travel. }\end{array}$ \\
\hline Gg14_222a & $\mathrm{C}-\mathrm{H}-\mathrm{K}$ & Mn-20 & $270-550$ & 127 & $\mathrm{Gg}-4$ & $300-780$ & $115^{*}$ & Oo-11 (+) & $350-530$ & $119^{*}$ & $\begin{array}{l}5-7 \text { whales with } 15-20 \\
\text { more whales scattered } \\
\text { in the area, traveling } \\
\text { with low activity level. }\end{array}$ \\
\hline
\end{tabular}

ID consists of two letters denoting the species (Gm, Globicephala macrorhynchus; Gg, Grampus grisieus), followed by a number representing year, and three numbers representing the Julian date of tag deployment; the final letter separates animals tagged on the same day. The exemplar is named using a two-letter system denoting species (Mn, Megaptera novaeangliae; Oo, Orcinus orca). Exemplars that are in bold resulted in a significant change in heading $(P<0.05)$; a minus sign $(-)$ indicates decreasing distance between the sound source and focal animal and a plus sign $(+)$ indicates increasing distance

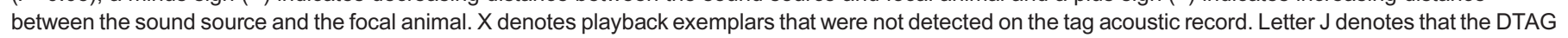
jettisoned before the call was played. An asterisk denotes potential shadowing of the signal by the tagged individual's body (determined by tag position on the animal and the animal's orientation relative to the source). 

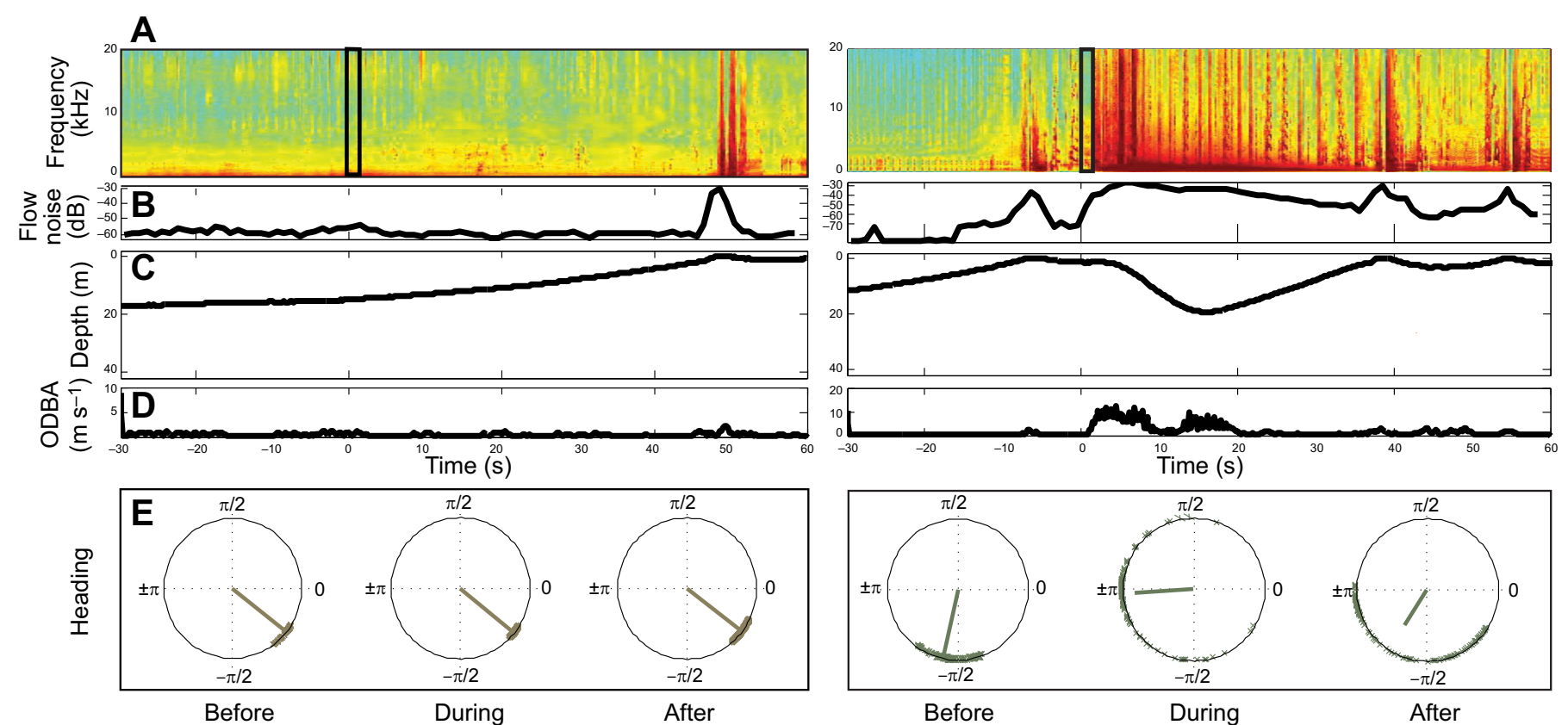

Fig. 1. Playback analysis. Examples of non-response (left, Gm12_162a) and response (right, Gm12_125a) of short-finned pilot whales to playbacks of mammaleating killer whale calls grouped into sound types with responses (right) and those without (left). The reactions included increased flow noise, overall dynamic body acceleration (ODBA) and heading variance. Each panel displays a 30 s period before, during and after presentation of a killer whale call and provides values for: (A) spectrogram of the acoustic record - the first received signal from the playback is highlighted with a black box; (B) flow noise, which is a proxy for the speed of the tagged animal; (C) depth profile of the tagged animal; (D) ODBA, which is a proxy for movement of the tagged animal; and (E) circular plots of heading of the tagged animal.

original data, where significant differences $(P \leq 0.05)$ indicate the presence of chaos (Theiler et al., 1992).

\section{Random Forest analysis}

We used a non-parametric Random Forest (RF) analysis to understand the relative contribution of each variable that might influence a response. RFs improve statistical prediction by generating a large number of bootstrapped decision trees (based on random samples of variables) and adopting a final result by combining the results across all the trees (Liaw and Wiener, 2002). We used the results of our animal response analysis to classify each playback as response (significant change in heading) or non-response (no significant change in heading) and evaluated the following predictive variables: species, group size, presence of calf, RL, stimulus order, ARTwarp classification and presence of multiple non-linearities in the call. We used the randomForest package (Liaw and Wiener, 2002) for analysis and ran the default value of 10,000 bootstrapped trees.

\section{RESULTS}

\section{Quantitative analysis of reactions}

Pilot whales were exposed to a total of nine complete playback sequences that included presentation of all three sets of stimuli (Table 1). Risso's dolphins were exposed to three complete playback sequences and one partial sequence (two playback sets) (Table 1). All the animals were tagged on the first approach except for Gm12_172a, which was tagged on the second approach. In both species, we observed no significant change in tagged animal heading relative to the source for any of the playbacks of conspecific calls or humpback whale social sounds (Table 1). Conversely, seven of the 14 animals in the playback experiments showed a response to killer whale calls that resulted in significant changes in tagged animal heading (Gm12_125a, $P<0.001$; Gm14_145a, $P=0.025$; Gm14_167a, $P=0.001 ; \quad \mathrm{Gm} 14 \_178 \mathrm{a}, \quad P<0.001 ; \quad \mathrm{Gm} 14 \_178 \mathrm{~b}$, $P<0.001$; Gg13_228b, $P<0.001$; Gg14_222a, $P<0.001)$. Analysis of individual playbacks showed that only playbacks of calls Oo-7, $-8,-10$ and -11 resulted in significant heading changes relative to the source, while all other call types did not (Fig. 2). It is important to note that the significant differences measured in responses in these conditions indicated movement toward the sound source for pilot whales (Fig. 3), but movement away from the sound source in Risso's dolphins (Fig. 3).

The response of both species to these call types included increases in speed, heading variance and ODBA (Fig. 1). Furthermore, pilot whale call rates increased (Fig. 4) and the focal pilot whales and their groups made directed movement towards the sound source. Risso's dolphins showed no measurable change in call rates (Fig. 4) but made very rapid directed movement away from the sound source. There were no correlations between the strong reaction and RL, estimated distance between the focal animal and sound source, or sequence of presented calls. Maximum received levels of the various playback exemplars ranged from 102 to $137 \mathrm{~dB}$ re. $1 \mu \mathrm{Pa}$ RMS (Table 1). For one conspecific (Gm-13) and two humpback (Mn-9 and Mn-17) exemplar sets, signals were not detected on the DTAG (Table 1). We did not observe a response at the time these exemplar sets were presented.

\section{Description of surface observations}

ODBA levels for pilot whales and Risso's dolphins were significantly higher during reactions to playbacks (Fig. 5). This suggests greater movement by the tagged animals during exposure to these calls, behavior that would be consistent with a rapid orienting response. Following the playback of killer whale call Oo-11 to pilot whale Gm12_125a, two sub-groups of whales 

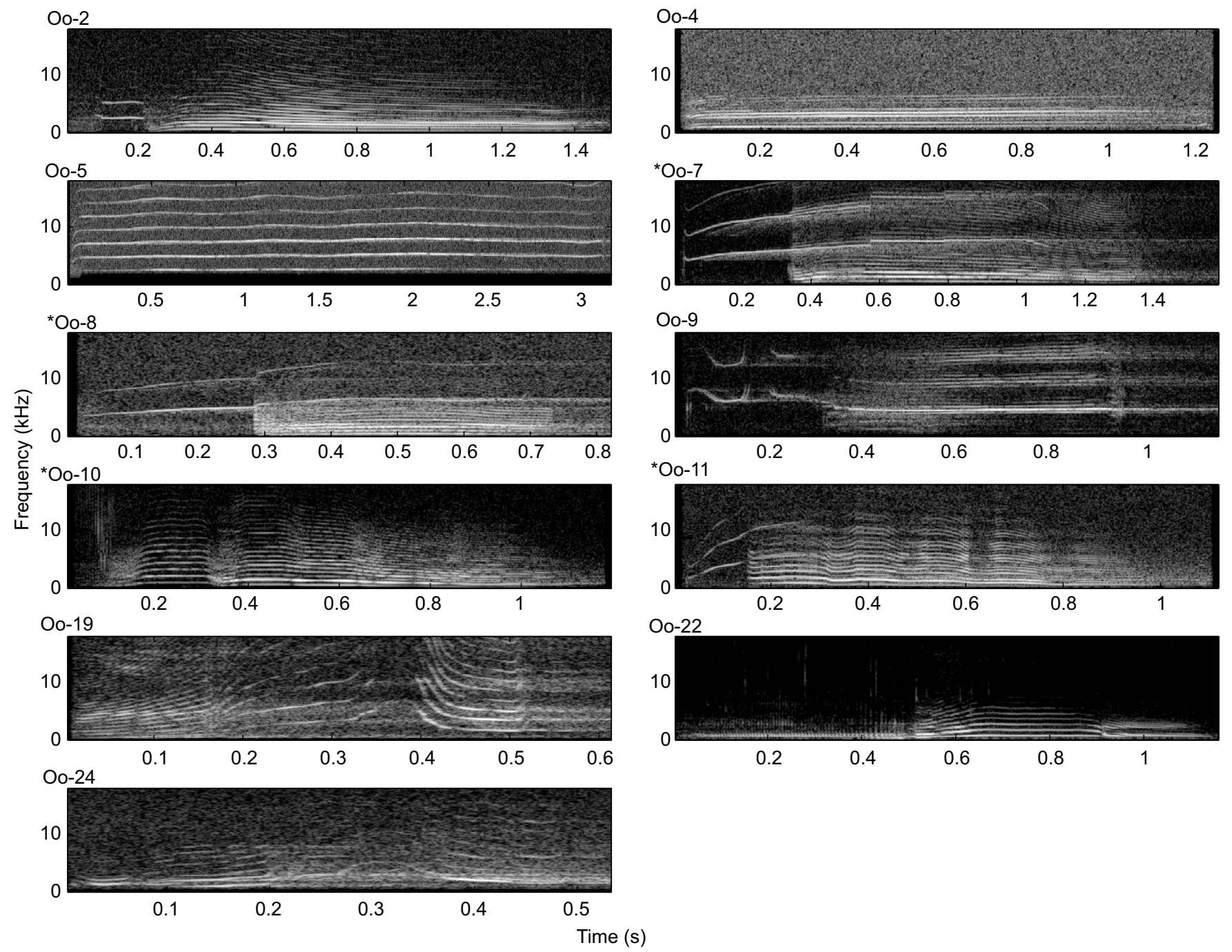

Fig. 2. Spectrograms of calls from mammal-eating killer whales used in playback experiments with short-finned pilot whales and Risso's dolphins. Playback exemplars are identified using the two-letter system denoting species (Oo, Orcinus orca) as in Table 1. *A strong response was observed during playback experiments.

coalesced quickly into a single, very tight group, with almost all whales in physical contact. The group then dived in unison, moving towards the sound source. We witnessed a similar response following the playback of killer whale call Oo-10 to pilot whale Gm14_145a; the focal group contracted, with almost all of the whales in physical contact. The group then moved in a coordinated and directed manner towards the sound source. In contrast, playbacks of the rest of the mammal-eating killer whale calls, as well as all of the conspecific and humpback calls evoked little or no obvious change in surface behavior from the focal animal or its group.

We also observed strong responses in two Risso's dolphins when playing the killer whale calls that elicited responses in pilot whales (Oo-10, -11). Here, sub-groups clustered together into a tight formation over the course of several minutes following exposure, before leaping at high speed away from the sound source for more than $10 \mathrm{~km}$. In both cases, the DTAG was shed before or just at the commencement of this rapid directional travel. This behavior has not been observed previously with this species in Southern California. We did not observe any change in surface behavior for the other two Risso's dolphins following playback of the mammal- eating killer whale calls that failed to elicit responses in pilot whales. Calls from conspecifics and humpbacks evoked no obvious change in surface behavior in the focal animal or its group for any of the four Risso's dolphins.

\section{Post hoc analysis of playback stimuli}

Five killer whale exemplars had multiple non-linear components (Table 2), including all four of the exemplars that elicited a response (Oo-7, -8, -10, -11). These four exemplars all included deterministic chaos and another non-linear component. Only one other call (Oo-2) contained deterministic chaos (but no other non-linear aspects) but did not elicit a reaction. Two of the calls our subjects reacted to $(\mathrm{Oo}-7,-8)$ had the same ARTwarp classification. One conspecific call (Gm-11) contained two non-linear components (subharmonics and frequency jumps) and five other conspecific calls and two humpback calls contained one non-linear component (Table 2). None of the calls from humpbacks or conspecifics contained deterministic chaos. Several of the exemplars were recorded on the same day, from the same group and potentially from the same individual (Table 2). Exemplars Oo-10 and Oo-11 were recorded on 27 July 2005 from the same group and may have been 


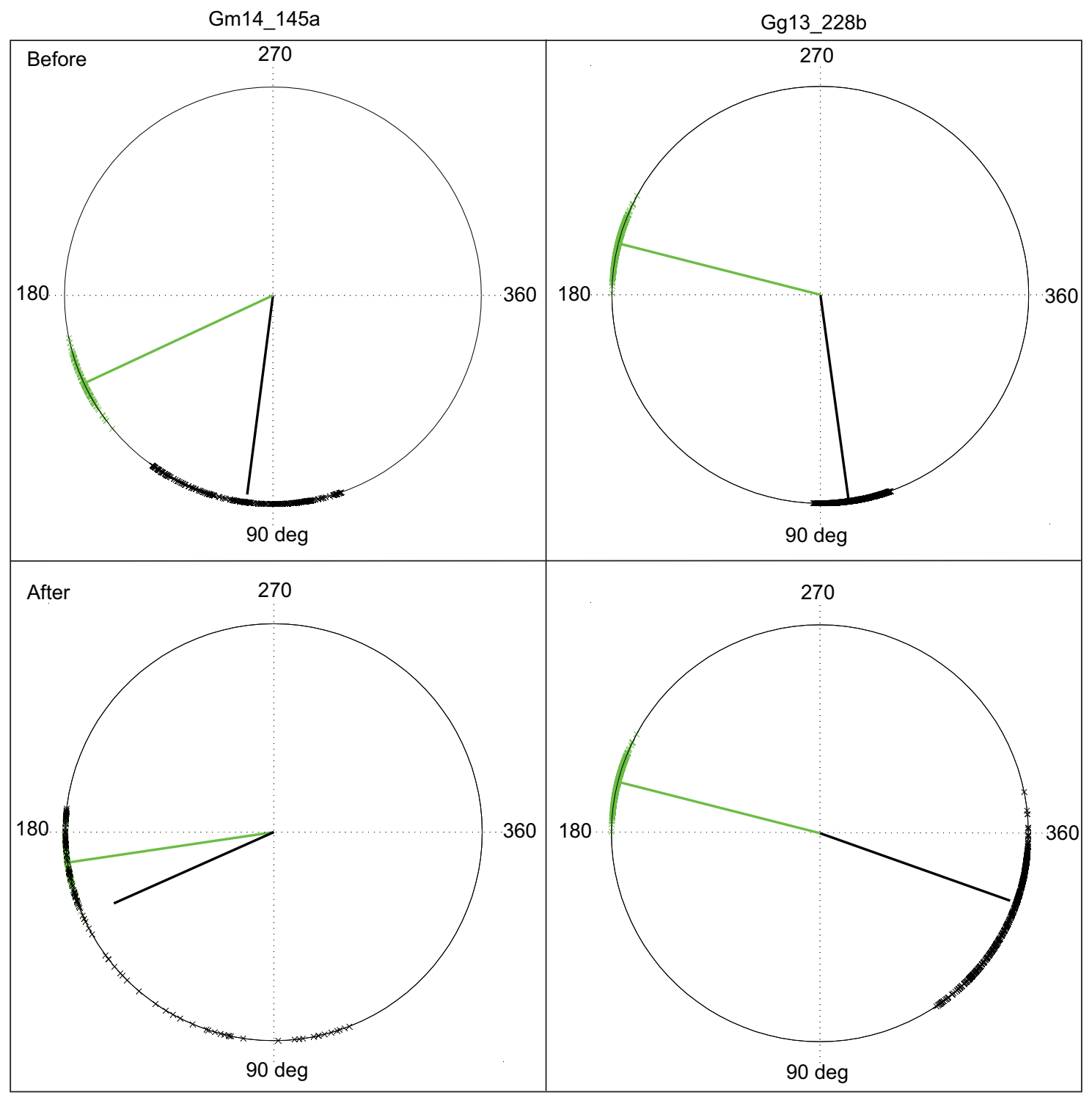

Fig. 3. Circular plots of heading relative to the sound source for $30 \mathrm{~s}$ before (top) and after (bottom) playbacks of killer whale exemplar Oo-10 to a pilot whale (left) and a Risso's dolphin (right). Bearing of the sound source (green) to the focal animal was determined using known location of the sound source and the estimated location of the focal animal as reconstructed from the focal follow points. Heading of the animal was obtained from the DTAG.

produced by the same individual. Exemplars Oo-7 and Oo-8 were recorded on 13 July 2005 and may have been produced by the same individual. Several calls that did not elicit a response were also recorded on 13 July $2005(\mathrm{Oo}-2,-4,-5,-9)$.

\section{Random Forest}

The RF analysis indicated that the two most important predictors of a response were the presence of multiple non-linearities and the ARTwarp classification of the killer whale call (Table 3). All other variables provided no improvement in the prediction of a response by either species of animal.

\section{DISCUSSION}

Short-finned pilot whales and Risso's dolphins reacted strongly but divergently to playback of a subset of calls from mammal-eating killer whales. Four calls (Oo-7, -8, -10, -11) elicited strong responses in short-finned pilot whales and two of these (Oo-10, -11) were also tested with Risso's dolphins in which they also elicited strong responses. Neither focal species responded to playback of other killer whale calls or to calls of conspecifics or humpback whales. Calls that elicited a response all included at least two non-linear phenomena. The response observed in both species involved increases in speed, heading variance and ODBA. In both species, the response appeared to include increased cohesion of the focal groups, but there were clear inter-species differences in their vocal and movement responses. The GEE showed that pilot whales increased ODBA and call counts during and/or after playbacks involving these calls. The pilot whales called more frequently and approached the sound source. Conversely, Risso's dolphins did not change their social call rates, and moved in a rapid, directed manner away from the source.

We acknowledge that the samples sizes for both species are small and that the playback exemplars used do not represent the full range of signals produced by these species. We also do not fully understand the behavioral contexts in which the calls of mammaleating killer whales were originally produced, which could create a 


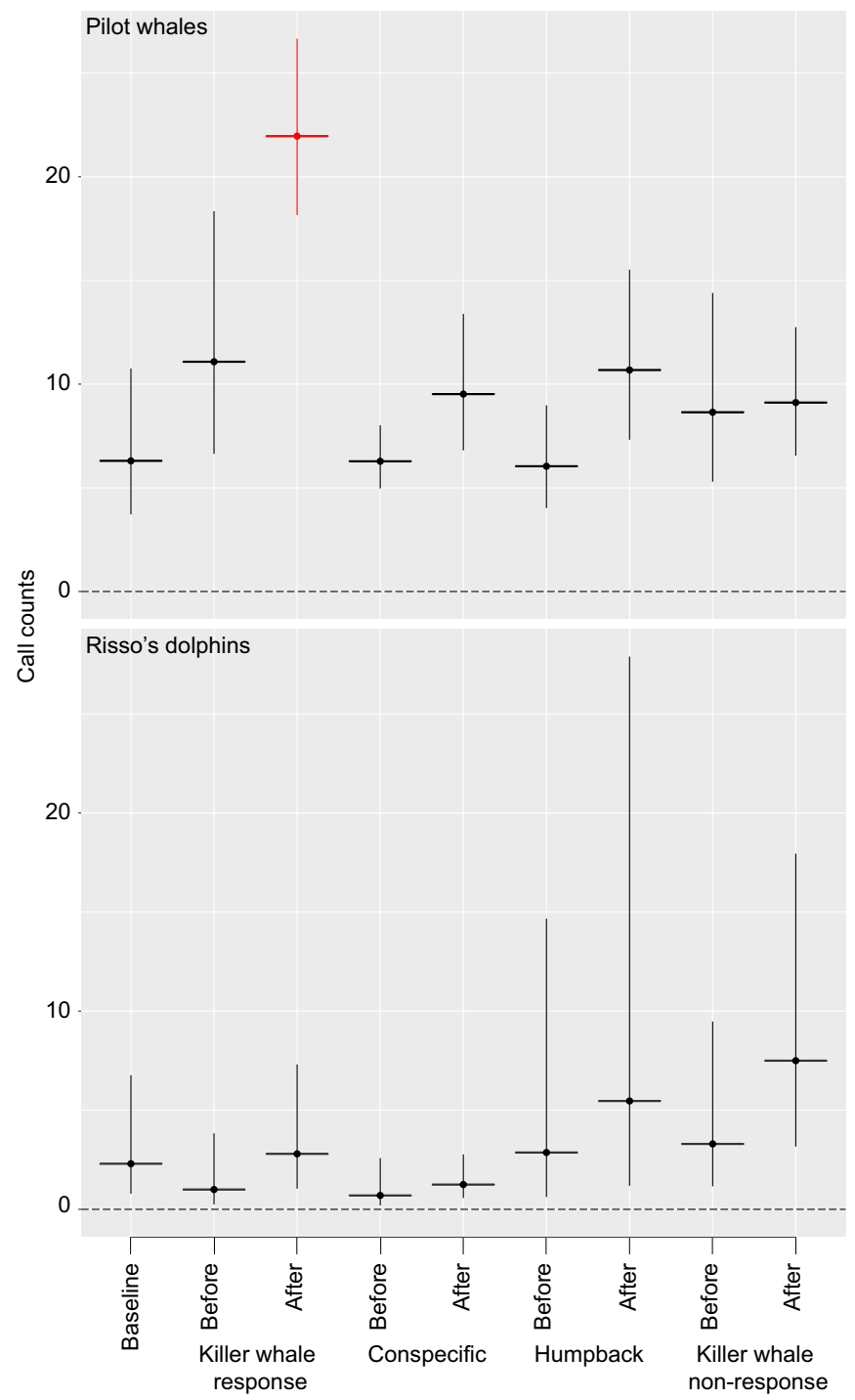

Fig. 4. Parameter estimates of Poisson general estimating equation (GEE) of pilot whale (top) and Risso's dolphin (bottom) call counts before and after playbacks of each stimulus type. Horizontal lines represent parameter estimates and vertical lines represent the 95\% confidence interval $(\mathrm{Cl})$ derived from parametric bootstrap of the fit parameters of the GEE. Call counts following playback of the group of mammal-eating killer whale calls that elicited a response (highlighted in red for pilot whales) were significantly higher than baseline or before levels. There were no significant changes in call counts following playback of any of the other stimulus types.

confounding effect if behavioral context differed systematically with playback condition. However, it seems unlikely that there are contexts in which cetaceans that are preyed upon by killer whales would not react to the sounds of foraging killer whales. The only exceptions in our study might be group size and RL as predictors of responsiveness, as there could be safety in numbers or at a certain distance from the calling predator. Nevertheless, our RF analysis showed that neither group size nor RL had a significant effect. Furthermore, we observed strong responses although we used a single point source while killer whales usually forage in groups. Thus, our signal could have been perceived as a single predator and yet we still saw strong responses.

Two other possible explanations for these results exist, but do not apply to our study. Schleidt (1961) developed a selective habituation hypothesis that predicts stronger responses to

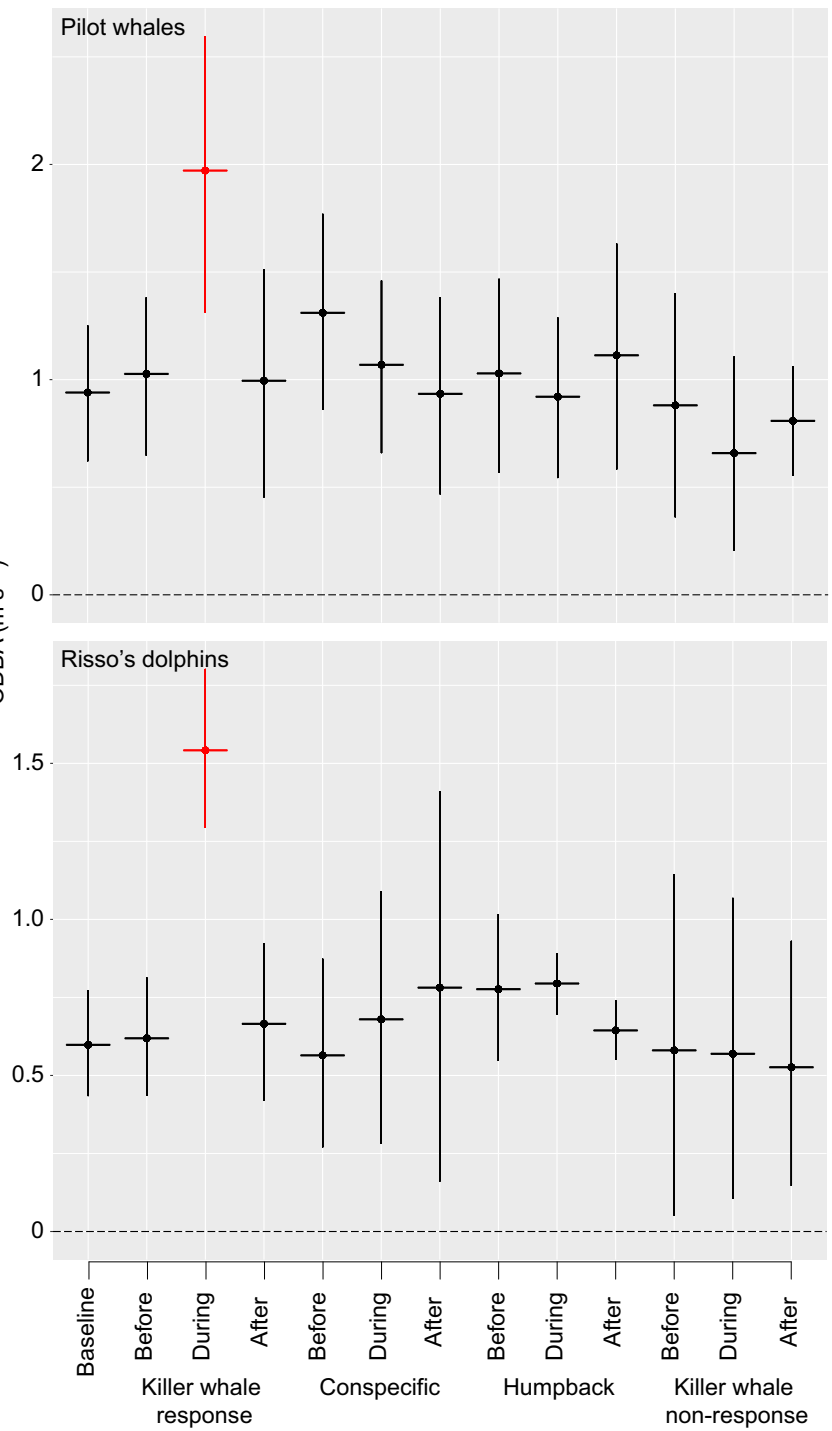

Fig. 5. Parameter estimates and $95 \% \mathrm{Cl}$ of Gaussian GEE for ODBA before, during and after playbacks of various exemplars to short-finned pilot whales (top) and Risso's dolphins (bottom). Horizontal lines represent parameter estimates and vertical lines represent the $95 \% \mathrm{Cl}$ derived from parametric bootstrap of the fit parameters of the GEE. OBDA levels during playback of the identified group of mammal-eating killer whale calls that elicited a response (highlighted in red) were significantly higher than baseline levels. No other period (before, during or after) for any other stimulus was found to be significantly different from baseline levels.

uncommon stimuli. This cannot explain our results because calls with non-linear phenomena are at least as common as those without such phenomena in the repertoire of killer whales (Tyson et al., 2007; Filatova et al., 2009). Alternatively, one could postulate that non-linear phenomena are specific to killer whales and therefore make species identification easier than for calls without such features. This would assume that calls without non-linear phenomena are not easily identified as coming from a killer whale and prey would therefore not recognize that killer whales are present. However, calls without non-linear phenomena that failed to elicit a response are more variable than calls with non-linear phenomena (Filatova et al., 2012) and the latter are not unique to killer whales (Quick et al., 2018). Thus, the most likely explanation is that the animals in our study responded to the non-linear aspects of the calls. 
Table 2. Classification of the killer whale exemplars and identification of non-linear components

\begin{tabular}{|c|c|c|c|c|c|c|}
\hline Exemplar & ARTwarp classification & Biphonation & Chaos & Subharmonics & Frequency jumps & Date recorded \\
\hline Oo-2 & WCT08 & & $\checkmark$ & & & 13-Jul-2005 \\
\hline Oo-4 & WCT11 & & & $\checkmark$ & & 13-Jul-2005 \\
\hline Oo-5 & Whistle/variable & & & & & 13-Jul-2005 \\
\hline Oo-8 & WCT03 & $\checkmark$ & $\checkmark$ & & $\checkmark$ & 13-Jul-2005 \\
\hline Oo-9 & Whistle/variable & & & $\checkmark$ & $\checkmark$ & 13-Jul-2005 \\
\hline Oo-10 & WCT02iii & & $\checkmark$ & & $\checkmark$ & 27-Jul-2005 \\
\hline Oo-24 & NASh06 & & & & & 28-Jun-2009 \\
\hline $\mathrm{Gm}-1$ & & & & $\checkmark$ & & 22-Mar-2006 \\
\hline $\mathrm{Gm}-5$ & & & & $\checkmark$ & & 22-Mar-2006 \\
\hline Gm-9 & & & & & & 22-Mar-2006 \\
\hline $\mathrm{Gm}-10$ & & $\checkmark$ & & & & 19-Apr-2008 \\
\hline $\mathrm{Gm}-11$ & & & & $\checkmark$ & $\checkmark$ & 19-Apr-2008 \\
\hline $\mathrm{Mn}-1$ & & & & & & 7-Jul-2006 \\
\hline $\mathrm{Mn}-4$ & & & & & & 11-Jul-2006 \\
\hline $\mathrm{Mn}-7$ & & & & & & 15-Jul-2006 \\
\hline$M n-9$ & & & & & & 15-Jul-2006 \\
\hline $\mathrm{Mn}-10$ & & & & & & 15-Jul-2006 \\
\hline $\mathrm{Mn}-14$ & & & & $\checkmark$ & & 8-Jul-2006 \\
\hline Mn-15 & & & & & $\checkmark$ & 8-Jul-2006 \\
\hline $\mathrm{Mn}-17$ & & & & & & 15-Jul-2006 \\
\hline $\mathrm{Mn}-18$ & & & & & & 15-Jul-2006 \\
\hline $\mathrm{Mn}-20$ & & & & & & 7-Jul-2006 \\
\hline $\mathrm{Mn}-21$ & & & & & & 7-Jul-2006 \\
\hline $\mathrm{Mn}-23$ & & & & & & 15-Jul-2006 \\
\hline Gg-1 & & & & & & 4-Aug-2011 \\
\hline
\end{tabular}

For ARTwarp classification, the set of letters prior to each number indicates the population of killer whales with WCT indicating west-coast transient and NASh indicating North Atlantic Shetland. A tick indicates the presence of the non-linear component from that column. The last column shows the date when the recording was made.

Biphonation and other non-linear phenomena, such as sub-harmonics, frequency jumps and deterministic chaos, are commonly found in alarm calls, and are known to elicit strong reactions in mammals (Fitch et al., 2002; Tyson et al., 2007). The unpredictability of non-linear phenomena in alarm calls may function as a way to prevent habituation (Fitch et al., 2002). In both mammals and birds, the addition of non-linearities to calls, synthesized non-linear sounds and unfamiliar non-linear biological calls have been shown to provoke reactions such as cessation of foraging and increased vigilance (Blumstein and Récapet, 2009; Blesdoe and Blumstein, 2014). All of the stimuli

Table 3. Variable importance determined in Random Forest analysis

\begin{tabular}{ll}
\hline Variable & Mean decrease accuracy \\
\hline Multiple non-linearities & 18.6 \\
ARTwarp classification & 11.8 \\
Stimulus order & -0.1 \\
Calf present & -0.1 \\
Distance & -0.2 \\
RL & -1.5 \\
Species & -4.3 \\
Group size & -5.7
\end{tabular}

The mean decrease accuracy reflects the reduction in accuracy if the variable was removed from a decision tree. that elicited a response contained at least two non-linear features and some contained three (e.g. Oo-7 exhibits frequency jumps, biphonation, subharmonics and deterministic chaos) and all four contained deterministic chaos.

Three of the four calls that elicited a response were classified as two-component calls. We are unable to say that biphonation elicited a response, but the function of these calls merits further investigation. Two-component calls have been described in all mammal-eating killer whale populations studied to date (Tyson et al., 2007; Filatova et al., 2012), and their behavioral and contextual usage implies that they function as group identifiers among mammal-eating killer whale pods (Filatova et al., 2009). The upper frequency component of these calls is more directional than the lower frequency component, which might allow a receiver to localize the caller based on the relative intensities of the two components in the call (Miller, 2006). While all stimuli in our experiment were played at the same source level, two-component calls in killer whales tend to have higher source levels than monophonic calls, further supporting the idea that these calls are used for group communication (Miller, 2006). Thus, these calls may indicate the presence of a large number of killer whales in the area, possibly following cooperative prey capture events, which could explain the strong reactions observed here in pilot whales and Risso's dolphins. 
In addition to deconstructing components of the calls that elicited a response in subjects in our playback experiments, one may ask whether these calls were recognized specifically as killer whale calls. Morton (1977) hypothesized that aversive calls have shared parameters across species, but there are many exceptions to this pattern, making its universal claim questionable (e.g. August and Anderson, 1987; Cardoso, 2011). Furthermore, it seems unlikely that predator avoidance would rely on the same mechanism as avoiding intra-specific aggression, because the two types of response require different reactions. Failure to avoid an aggressive conspecific will likely carry different costs than failure to respond to an attempted predation event. Non-linear calls are not uncommon in cetacean call repertoires, so this is a question that can be tested experimentally. Pilot whale calls share some characteristics with those of killer whales, including biphonation and other non-linear phenomena (Sayigh et al., 2013). In our study, the exemplar Gm-10 was a two-component call, and several pilot whale calls included subharmonics (Gm-1, -5, -11, -13,-16). Gm-11 contained both subharmonics and frequency jumps. The lack of response to conspecific calls that shared non-linear phenomena with killer whale calls suggests that our subjects could discriminate a killer whale call from a conspecific call. Furthermore, the lack of response to non-linear features in some of the humpback whale calls suggests that the subjects in the playback experiments could differentiate predator from non-predator calls. Our sample sizes here are admittedly limited, but they suggest that the response was based not only on aversive parameters in calls but also on a recognition of calls coming from a predator. A previous study on fish-eating killer whales hypothesized that approaches by pilot whales might be mobbing behavior, but it lacked the conspecific control that would have shown whether pilot whales mobbed in response to killer whale calls or were attracted to calls that sounded like those of a conspecific (Curé et al., 2012). The lack of response of pilot whales to conspecific calls in our study supports the idea that the approach behavior following playback of mammal-eating killer whale calls was indeed an anti-predator response rather than an attraction to calls similar to their own. However, the exact role of different non-linear features needs further examination, because it appeared that a combination of such features carried the key information for reactions in our study.

Other researchers have noted general similarities with and frequency overlap between tactical mid-frequency active sonar (MFAS) signals and those produced by mammal-eating killer whales (Zimmer and Tyack, 2007; Tyack et al., 2011). MFAS may also share some other characteristics with these calls, including asynchronous tonal and frequency-modulated elements (D'Spain et al., 2006). Playback experiments from controlled-exposure experiments on free-ranging cetaceans, primarily using anthropogenic sources of sound, have elicited similar reactions to those described in this paper. For example, a Cuvier's beaked whale (Ziphius cavirostris) responded to simulated MFAS by stopping vocalization, rapid directed movement away from the sound source and an extended dive duration with slow ascent, with some of these behavioral changes lasting well after the end of the exposure (DeRuiter et al., 2013). Avoidance responses to simulated MFAS have been recorded in several other species of cetaceans (Goldbogen et al., 2013; Stimpert et al., 2014; Miller et al., 2014). Pilot whales responded to MFAS exposure and to the sounds of predators (Tyack, 2009; Miller et al., 2012) in a similar manner to the response we observed. For example, the response of short-finned pilot whales to simulated MFAS signals in a behavioral-response study (Southall et al., 2008) was reminiscent of a social defense strategy, which included elevated vocalization rate and increased group cohesion (Tyack, 2009). The response of both focal species occurred in a manner consistent with their patterns of social organization. Pilot whales, which live in relatively permanent groups characterized by strong social bonds (Heimlich-Boran, 1993; Alves et al., 2013; Mahaffy et al., 2015), responded by increasing social cohesion. Risso's dolphins, which have a social structure that shows less permanence in terms of social affiliations and is characterized by more fluidity (Hartman et al., 2008), displayed an exaggerated flight response, moving rapidly away from the sound source.

Both species appeared to discriminate amongst different call types from another species, the killer whale. This is the first demonstration of such an ability in cetaceans. These results do not unequivocally demonstrate that the two focal species have a stereotyped anti-predator response or that the sole determinant of the probability of a response to killer whale calls is the presence or absence of non-linear components. Nor do these results prove that the strong responses observed to other external stimuli, including MFAS, are necessarily the result of animals categorizing those sounds in the same general class as the calls of predators. However, the responses of both species to signals that share a specific call structure is striking. In our view, these findings suggest that pilot whales and Risso's dolphins are capable of assessing threat levels from call usage by their main predator, using structural features other than the general frequencymodulation pattern relevant in killer whale call dialects when classifying predator calls.

\section{Acknowledgements}

We thank all members of the field team for tagging and tracking pilot whales; in particular, Zach Swaim, Heather Foley and Danielle Waples. Valuable advice, assistance and recordings of call exemplars were provided by Volker Deecke, Alison Stimpert and Lynn Williams Hodge. We thank Stacy De Ruiter, Catriona Harris and Len Thomas for their assistance and support with analysis through the MOCHA project.

\section{Competing interests}

The authors declare no competing or financial interests.

\section{Author contributions}

Conceptualization: A.S.F., V.M.J., D.N., B.S., A.J.R.; Methodology: M.T.B., V.M.J., B.S., A.J.R.; Formal analysis: M.T.B., N.J.Q.; Investigation: A.S.F., D.N., N.J.Q., B.S., A.J.R.; Data curation: N.J.Q.; Writing - original draft: M.T.B.; Writing - review \& editing: M.T.B., A.S.F., V.M.J., D.N., N.J.Q., B.S., A.J.R.; Visualization: M.T.B.; Supervision: D.N., A.J.R.; Project administration: B.S., A.J.R.; Funding acquisition: A.S.F., D.N., B.S., A.J.R.

\section{Funding}

This research was supported by award RC-2154 from the Strategic Environmental Research and Development Program and funding from the Naval Facilities Engineering Command Atlantic and National Oceanic and Atmospheric Administration Fisheries, Southeast Region.

\section{References}

Altmann, J. (1974). Observational study of behavior: sampling methods. Behaviour 49, 227-266.

Alves, F., Quérouil, S., Dinis, A., Nicolau, C., Ribeiro, C., Freitas, L., Kaufmann, M. and Fortuna, C. (2013). Population structure of short-finned pilot whales in the oceanic archipelago of Madeira based on photo-identification and genetic analyses: implications for conservation. Aquat. Conserv. 23, 758-776.

August, P. V. and Anderson, J. G. (1987). Mammal sounds and motivationstructural rules: a test of the hypothesis. J. Mammal. 68, 1-9.

Berens, P. (2009). CircStat: a MATLAB toolbox for circular statistics. J. Stat. Soft. 31, 1-21.

Blesdoe, E. K. and Blumstein, D. T. (2014). What is the sound of fear? Behavioral responses of white-crowned sparrows Zonotrichia leucophrysto synthesized nonlinear acoustic phenomena. Curr. Zool. 60, 534-541.

Blumstein, D. T. and Récapet, C. (2009). The sound of arousal: the addition of novel non-linearities increases responsiveness in marmot alarm calls. Ethology $115,1074-1081$ 
Cantwell, L. R., Johnson, W. T. I., Kaschel, R. E., Love, D. J. and Freeberg, T. M (2016). Predator-risk-sensitive foraging behavior of Carolina chickadees (Poecile carolinensis) and tufted titmice (Baeolophus bicolor) in response to the head orientation of snake predator models. Behav. Ecol. Sociobiol. 70, 533-539.

Cardoso, G. C. (2011). Paradoxical calls: the opposite signaling role of sound frequency across bird species. Behav. Ecol. 23, 237-241.

Caro, T. (2005). Antipredator Defenses in Birds and Mammals. Chicago, IL: University of Chicago Press.

Curé, C., Antunes, R., Samarra, F., Alves, A. C., Visser, F., Kvadsheim, P. H. and Miller, P. J. O. (2012). Pilot whales attracted to killer whale sounds: acousticallymediated interspecific interactions in cetaceans. PLOS ONE 7, e52201.

Curé, C., Sivle, L. D., Visser, F., Wensveen, P. J., Isojunno, S., Harris, C. M., Kvadsheim, P. H., Lam, F.-P. A. and Miller, P. J. O. (2015). Predator sound playbacks reveal strong avoidance responses in a fight strategist baleen whale. Mar. Ecol. Prog. Ser. 526, 267-282.

De Boer, H. Y., Van Breukelen, L., Hootsmans, M. J. M. and Van Wieren, S. E. (2004). Flight distance in roe deer Capreolus capreolus and fallow Deer Dama dama as related to hunting and other factors. Wildlife Biol. 10, 35-41.

de Bruyn, P. J. N., Tosh, C. A. and Terauds, A. (2013). Killer whale ecotypes: is there a global model? Bio. Rev. 88, 62-80.

Deecke, V. B. (2003). The vocal behaviour of transient killer whales (Orcinus orca) communicating with costly calls. PhD thesis, University of St Andrews.

Deecke, V. B., Ford, J. K. and Spong, P. (2000). Dialect change in resident killer whales: implications for vocal learning and cultural transmission. Anim. Behav. 60, 629-638.

Deecke, V. B. (2006). Studying marine mammal cognition in the wild: a review of four decades of playback experiments. Aquat. Mamm. 32, 461-482.

Deecke, V. B. and Janik, V. M. (2006). Automated categorization of bioacoustic signals: avoiding perceptual pitfalls. J. Acoust. Soc. Am. 119, 645-653.

Deecke, V. B., Slater, P. J. B. and Ford, J. K. B. (2002). Selective habituation shapes acoustic predator recognition in harbour seals. Nature 420, 171-173.

Deecke, V. B., Ford, J. K. B. and Slater, P. J. B. (2005). The vocal behaviour of mammal-eating killer whales: communicating with costly calls. Anim. Behav. 69, 395-405

Deecke, V. B., Nykänen, M., Foote, A. D. and Janik, V. M. (2011). Vocal behaviour and feeding ecology of killer whales Orcinus orca around Shetland, UK. Aquat Biol. 13, 79-88

DeRuiter, S. L., Southall, B. L., Calambokidis, J., Zimmer, W. M. X., Sadykova, D., Falcone, E. A., Friedlaender, A. S., Joseph, J. E., Moretti, D., Schorr, G. S. et al. (2013). First direct measurements of behavioural responses by Cuvier's beaked whales to mid-frequency active sonar. Biol. Lett. 9, 20130223-20130223.

D'Spain, G. L., D'Amico, A. and Fromm, D. M. (2006). Properties of the underwater sound fields during some well documented beaked whale mass stranding events. J. Cetac. Res. 7, 223-238.

Etting, S. F. and Isbell, L. A. (2014). Rhesus macaques (Macaca mulatta) use posture to assess level of threat from Snakes. Ethology 120,1177-1184

Favaro, L., Neves, S., Furlatic, S., Pessani, D., Martic, V. and Janik, V. M. (2016) Evidence suggests vocal production learning in a cross-fostered Risso's dolphin (Grampus griseus). Anim. Cogn. 19, 847-853

Filatova, O. A., Fedutin, I. D., Nagaylik, M. M., Burdin, A. M. and Hoyt, E. (2009) Usage of monophonic and biphonic calls by free-ranging resident killer whales (Orcinus orca) in Kamchatka, Russian Far East. Acta Ethol. 12, 37-44.

Filatova, O. A., Deecke, V. B., Ford, J. K. B., Matkin, C. O., Barrett-Lennard, L. G., Guzeev, M. A., Burdin, A. M. and Hoyt, E. (2012). Call diversity in the North Pacific killer whale populations: implications for dialect evolution and population history. Anim. Behav. 83, 595-603.

Fitch, W. T., Neubauer, J. and Herzel, H. (2002). Calls out of chaos: the adaptive significance of nonlinear phenomena in mammalian vocal production. Anim. Behav. 63, 407-418.

Ford, J. K. B. (1989). Acoustic behavior of resident killer whales (Orcinus Orca) Off Vancouver Island, British-Columbia. Can. J. Zool. 67, 727-745.

Ford, J. K. B. and Ellis, G. M. (2014). You are what you eat: Foraging specializations and their influence on the social organization and behavior of killer whales. In Primates and Cetaceans (ed. J. Yamagiwa and L. Karczmarski), pp. 75-98. New York: Springer.

Ford, J. K., Ellis, G. M., Barrett-Lennard, L. G., Morton, A. B., Palm, R. S. and Balcomb, K. C., III (1998). Dietary specialization in two sympatric populations of killer whales (Orcinus orca) in coastal British Columbia and adjacent waters. Can. J. Zool. 76, 1456-1471.

Goldbogen, J. A., Southall, B. L., DeRuiter, S. L., Calambokidis, J., Friedlaender, A. S., Hazen, E. L., Falcone, E. A., Schorr, G. S., Douglas, A. Moretti, D. J. et al. (2013). Blue whales respond to simulated mid-frequency military sonar. Roy. Proc. Soc. B. 280, 20130657

Güntürkün, O. (2014). Is dolphin cognition special? Brain Behav. Evol. 83, 177-180. Hartman, K. L., Visser, F. and Hendriks, A. J. E. (2008). Social structure of Risso's dolphins (Grampus griseus) at the Azores: a stratified community based on highly associated social units. Can. J. Zool 86, 294-306.

Heimlich-Boran, J. R. (1993). Social organisation of the short-finned pilot whale, Globicephala macrorhynchus, with special reference to the comparative socia ecology of Delphinids. PhD thesis, University of Cambridge, Cambridge, UK.
Helfman, G. S. (1989). Threat-sensitive predator avoidance in damselfishtrumpetfish interactions. Behav. Ecol. Sociobiol. 24, 47-58.

Højsgaard, S., Halekoh, U. and Yan, J. (2006). Geepack: the R package geepack for Generalized Estimating Equations. J. Stat. Soft. 15, 1-11.

Isojunno, S., Curé, C., Kvadsheim, P. H., Lam, F.-P. A., Tyack, P. L., Wensveen, P. J. and Miller, P. J. O. (2016). Sperm whales reduce foraging effort during exposure to 1-2 kHz sonar and killer whale sounds. Ecol. Appl. 26, 77-93.

Jefferson, T. A., Stacey, P. J. and Baird, R. W. (1991). A review of Killer Whale interactions with other marine mammals: predation to co-existence. Mamm. Rev. 21, 151-180

Johnson, M. P. and Tyack, P. L. (2003). A digital acoustic recording tag for measuring the response of wild marine mammals to sound. J. Ocean Eng. 28, 3-12. Liaw, A. and Wiener, M. (2002). Classification and regression by randomForest. $R$ News 2, 18-22.

Madsen, J. and Fox, A. D. (1995). Impacts of hunting disturbance on waterbirds - a review. Wildl. Biol. 1, 193-207.

Mahaffy, S. D., Baird, R. W., McSweeney, D. J., Webster, D. L. and Schorr, G. S. (2015). High site fidelity, strong associations, and long-term bonds: short-finned pilot whales off the island of Hawai'i. Mar. Mam. Sci. 31, 1427-1451.

Mathot, K. J., van den Hout, P. J. and Piersma, T. (2009). Differential responses of red knots, Calidris canutus, to perching and flying sparrowhawk, Accipiter nisus models. Anim. Behav 77, 1179-1185.

Miller, P. J. O. (2006). Diversity in sound pressure levels and estimated active space of resident killer whale vocalizations. J. Comp. Phys. A 192, 449-459.

Miller, P. J., Kvadsheim, P. H., Lam, F.-P. A., Wensveen, P. J., Antunes, R. Alves, A. C., Visser, F., Kleivane, L., Tyack, P. L. and Silve, L. D. (2012). The severity of behavioral changes observed during experimental exposures of kille (Orcinus orca), long-finned pilot (Globicephala melas), and sperm (Physeter macrocephalus) whales to naval sonar. Aquat. Mamm. 38, 362-401.

Miller, P. J. O., Antunes, R. N., Wensveen, P. J., Samarra, F. I. P., Alves, A. C. Tyack, P. L., Kvadsheim, P. H., Kleivane, L., Lam, F.-P. A., Ainslie, M. A. et al. (2014). Dose-response relationships for the onset of avoidance of sonar by freeranging killer whales. J. Acoust. Soc. of Am. 135, 975-993.

Morton, E. S. (1977). On the occurrence and significance of motivation-structural rules in some bird and mammal sounds. Am. Nat. 111, 855-869.

Qasem, L., Cardew, A., Wilson, A., Griffiths, I., Halsey, L. G., Shepard, E. L. C., Gleiss, A. C. and Wilson, R. (2012). Tri-axial dynamic acceleration as a proxy for animal energy expenditure; should we be summing values or calculating the vector? PLoS ONE 7, e31187.

Quick, N. J., Scott-Hayward, L. A. S., Sadykova, D., Nowacek, D. and Read, A. (2017). Effects of a scientific echo sounder on the behavior of short-finned pilot whales (Globicephala macrorhynchus). Can. J. Fish. Aquat. Sci. 74, 716-726.

Quick, N. J., Callahan, H. S. and Read, A. (2018). Two-component calls in short-finned pilot whales (Globicephala macrorhynchus). Mar. Mam. Sci. 34, 155-168.

Saulitis, E., Matkin, C., Barrett Lennard, L., Heise, K. and Ellis, G. (2000) Foraging strategies of sympatric killer whale (Orcinus orca) populations in Prince William Sound, Alaska. Mar. Mam. Sci. 16, 94-109.

Sayigh, L., Quick, N., Hastie, G. and Tyack, P. L. (2013). Repeated call types in short-finned pilot whales, Globicephala macrorhynchus. Mar. Mam. Sci. 29, 312-324.

Schleidt, W. M. (1961). Über die Auslösung der Flucht vor Raubvögeln be Truthühnern. Naturwissenschaften 48,141-142a.

Simon, M., Johnson, M., Tyack, P. L. and Madsen, P. T. (2009). Behaviour and kinematics of continuous ram filtration in bowhead whales (Balaena mysticetus) Roy. Proc. Soc. B. 276, 3819-3828.

Sivle, L. D., Wensveen, P. J., Kvadsheim, P. H., Lam, F. P. A., Visser, F., Curé, C., Harris, C. M., Tyack, P. L. and Miller, P. J. (2016). Naval sonar disrupts foraging in humpback whales. Mar. Ecol. Prog. Ser. 562, 211-220.

Soto, N. A., Johnson, M. P., Madsen, P. T., Díaz, F., Domínguez, I., Brito, A. and Tyack, P. L. (2008). Cheetahs of the deep sea: deep foraging sprints in shortfinned pilot whales off Tenerife (Canary Islands). J. Anim. Ecol. 77, 936-947.

Soto, N. A., Madsen, P. T., Tyack, P., Arranz, P., Marrero, J., Fais, A., Revelli, E. and Johnson, M. (2012). No shallow talk: cryptic strategy in the vocal communication of Blainville's beaked whales. Mar. Mamm. Sci. 28, E75-E92.

Southall, B., Boyd, I., Tyack, P. L. and Wartzock, D. (2008). Deep-diving odontocetes behavioral-response study (BRS). Bioacoustics 17, 186-188.

Stankowich, T. and Blumstein, D. T. (2005). Fear in animals: a meta-analysis and review of risk assessment. R. Proc. Soc. B. 272, 2627-2634.

Stimpert, A. K., DeRuiter, S. L., Southall, B. L., Moretti, D. J., Falcone, E. A Goldbogen, J. A., Friedlaender, A., Schorr, G. S. and Calambokidis, J. (2014) Acoustic and foraging behavior of a Baird's beaked whale, Berardius bairdii, exposed to simulated sonar. Sci. Rep. 4, 7031.

Swaisgood, R. R., Rowe, M. P. and Owings, D. H. (1999). Assessment of rattlesnake dangerousness by California ground squirrels: exploitation of cues from rattling sounds. Anim. Behav. 57, 1301-1310.

Theiler, J., Eubank, S., Longtin, A., Galdrikian, B. and Farmer, J. D. (1992) Testing for nonlinearity in time series: the method of surrogate data. Physica $D$. 58, 77-94.

Thiel, D., Ménoni, E., Brenot, J.-F. and Jenni, L. (2007). Effects of recreation and hunting on flushing distance of capercaillie. J. Wildlife Man. 71, 1784-1792. 
Tyack, P. L. (2009). Human-generated sound and marine mammals. Phys. Today 62, 39-44.

Tyack, P. L., Zimmer, W. M., Moretti, D., Southall, B. L., Claridge, D. E., Durban, J. W., Clark, C. W., D'Amico, A., DiMarzio, N., Jarvis, S. et al. (2011). Beaked whales respond to simulated and actual navy sonar. PLOS ONE 6, e17009.

Tyson, R. B., Nowacek, D. P. and Miller, P. J. O. (2007). Nonlinear phenomena in the vocalizations of North Atlantic right whales (Eubalaena glacialis) and killer whales (Orcinus orca). J. Acoust. Soc. Am. 122, 1365-1373.
Visser, F., Curé, C., Kvadsheim, P. H., Lam, F.-P. A., Tyack, P. L. and Miller, P. J. O. (2016). Disturbance-specific social responses in long-finned pilot whales, Globicephala melas. Sci. Rep. 6, 28641.

Williamson, M. J., Kavanagh, A. S., Noad, M. J., Kniest, E. and Dunlop, R. A. (2016). The effect of close approaches for tagging activities by small research vessels on the behavior of humpback whales (Megaptera novaeangliae). Mar Mamm. Sci. 32, 1234-1253.

Zimmer, W. M. and Tyack, P. L. (2007). Repetitive shallow dives pose decompression risk in deep-diving beaked whales. Mar. Mam. Sci. 23, 888-925 